\title{
Crohn's Disease of the Esophagus, Duodenum, and Stomach
}

\author{
David M. Schwartzberg, MD ${ }^{1}$ Stephen Brandstetter, MD ${ }^{1} \quad$ Alexis L. Grucela, MD, FACS, FASCRS² \\ ${ }^{1}$ Department of Colorectal Surgery, Digestive Disease Institute, \\ Cleveland Clinic Foundation, Cleveland, Ohio \\ 2 Division of Colon and Rectal Surgery, New York University Langone \\ Medical Center, New York, New York

\begin{abstract}
Address for correspondence Alexis L. Grucela, MD, FACS, FASCRS, Division of Colon and Rectal Surgery, New York University Langone Medical Center, 530 1st Avenue, Suite 7V, New York, NY 10016 (e-mail: Alexis.Grucela@NYUMC.org).
\end{abstract}

Clin Colon Rectal Surg 2019;32:231-242.

\begin{abstract}
Keywords

- Upper

Gastrointestinal

Crohn's Disease

- gastroduodenal

Crohn's disease

- esophageal Crohn's disease

- strictureplasty

Upper gastrointestinal Crohn's is an under-reported, under-recognized phenotype of Crohn's disease. Routine screening in the pediatric population has shown a higher prevalence compared with adults; however, most adult patients remain asymptomatic with respect to upper gastrointestinal Crohn's disease. For the patients who are symptomatic, medical treatment is the first line of management, except for cases of obstruction, perforation, or bleeding. Though most patients respond to medical therapy, mainly steroids, with the addition of immunomodulators and more recently biologics agents, surgical intervention is usually required only for obstructing gastroduodenal disease secondary to strictures. Strictureplasty and bypass are safe operations with comparable morbidity, although bypass has higher rates of dumping syndrome and marginal ulceration in the long term. Rare cases of gastroduodenal fistulous disease from active distal disease may involve the stomach or duodenum, and esophageal Crohn's disease can fistulize to surrounding structures in the mediastinum which may require the highly morbid esophagectomy.
\end{abstract}

Since Crohn and colleagues first identified and categorized "regional ileitis" as a disease solely of the small bowel in 1932, subsequent literature has characterized an epithet for Crohn's disease (CD) as occurring anywhere from oral cavity to anus. ${ }^{1}$ The vast literature reported on $\mathrm{CD}$ has been sparse on upper gastrointestinal (UGI) involvement by CD, defined as esophagitis, gastritis, and duodenitis, which was first expanded to include UGI pathology by Comfort et al in $1950 .^{2-4}$ Research has shed light on the natural history of CD; however, it remains an idiopathic chronic inflammatory bowel disease (IBD) originating from a complex relationship of environmental, microbial, and genetic factors. ${ }^{5,6} \mathrm{CD}$ makes up one of the two predominant classifications of IBD along with ulcerative colitis (UC) and indeterminate colitis (IC) having features of both. Historically, UGI-IBD was synonymous with $\mathrm{CD}$; however, UC has been implicated with pathology in the proximal GI tract as well. ${ }^{7}$ Both $\mathrm{CD}$ and UC typically affect distal bowel with UC predominantly manifesting in the colon and rectum, and CD primarily in the distal small bowel (terminal ileum).

The prevalence of $C D$ in North America in recent studies is 26 to 198 cases per 100,000 persons, with an incidence of 3.1 to 14.6 per 100,000 person-years. ${ }^{5,8,9} \mathrm{CD}$ has a slight female predominance in North America. ${ }^{5}$ The age of onset for both CD and UC fits a bimodal distribution around ages 20 and 50 years. Studies have shown a predominant age of onset for $C D$ in the lower age peak of the classic bimodal distribution, or have shown a unimodal distribution near age 20 years. ${ }^{5}$

\section{Upper Gastrointestinal Involvement in IBD}

Upper gastrointestinal CD is uncommon and has been reported to range from 0.3 to $5 \%$ of affected adult patients. Though under-reported, and overall less frequent than ileal disease, Goodhand et al examined UGI-CD, and found that it is more frequent in the adolescent literature, which could be
Issue Theme Complex Crohn's Disease: Primum non nocere; Guest Editor: Michael A. Valente, DO, FACS, FASCRS
Copyright (c) 2019 by Thieme Medical Publishers, Inc., 333 Seventh Avenue, New York, NY 10001, USA. Tel: +1(212) 584-4662.
DOI https://doi.org/ 10.1055/s-0039-1683850. ISSN 1531-0043. 
secondary to more frequent upper endoscopy, with almost $28 \%$ of adolescent CD patients having UGI involvement. ${ }^{10}$ Significantly earlier onset of CD has been found in patients with predominant UGI-CD at diagnosis, ${ }^{11,12}$ and pediatric patients with CD have a higher rate of UGI-CD. ${ }^{13,14}$ A study of use of prospective esophagogastroduodenoscopy (EGD) in adult IBD patients showed the incidence of foregut CD was $41 \%$ in patients with previously confirmed CD and only $32 \%$ of patients were symptomatic. ${ }^{15}$ A study 20 years prior where prospective EGD was undertaken on 41 patients showed $56 \%$ of $C D$ patients to have endoscopic abnormalities including aphthoid erosions, ulcers, and mucosal thickening. ${ }^{16}$ Granulomas were found in only $20 \%$ of specimens, with some literature reporting a range between 4 and $83 \%$, and are therefore not diagnostic in UGI-CD. ${ }^{17}$ Granulomas were, however, more frequently found in patients who had other concomitant endoscopic abnormalities than without (26 vs. $11 \%)^{17}$

The differential for upper GI granulomatous disease is vast and some differentials are Helicobacter pylori, peptic ulcer disease, gastric carcinoma, gastric lymphoma, sarcoidosis, tuberculosis, and syphilis, among others listed in - Table 1. ${ }^{17}$ Patients with UGI-CD manifestations have been shown to have higher rates of structuring disease, penetrating disease, recurrences, hospitalizations, and surgical interventions; thus, UGI-CD is somewhat of an overall prognostic factor for CD. ${ }^{18,19}$ In a study by Sakuraba et al, $70 \%$ of patients with distal CD and any UGI symptoms (epigastric pain, reflux, nausea, physician discretion) who underwent diagnostic EGD were found to have CD-related pathology. ${ }^{20}$ These findings make clear that foregut symptomatology requires further evaluation in patients with CD.

EGD with biopsy is also recommended in patients who have a clinical picture concerning for IBD, but who are deemed indeterminate after evaluation including clinical examination, laboratory and radiographic tests, and colonoscopy with biopsy and histologic examination, as this may aid in clarifying the diagnosis. ${ }^{21}$ Castellaneta et al undertook prospective EGD of 65 children with $C D$, finding a $31 \%$ rate of

Table 1 Differential diagnosis in upper gastrointestinal Crohn's disease

\begin{tabular}{|l|l|l|}
\hline $\begin{array}{l}\text { Gastroesophageal } \\
\text { reflux }\end{array}$ & $\begin{array}{l}\text { Helicobacter } \\
\text { pylori }\end{array}$ & $\begin{array}{l}\text { Hypertrophic } \\
\text { gastropathy }\end{array}$ \\
\hline Pill-contact ulcers & Cytomegalovirus & $\begin{array}{l}\text { Eosinophilic } \\
\text { gastritis }\end{array}$ \\
\hline Malignancy & $\begin{array}{l}\text { Behcet's } \\
\text { syndrome }\end{array}$ & $\begin{array}{l}\text { Wegener's } \\
\text { granulomatosis }\end{array}$ \\
\hline Fungal disease & $\begin{array}{l}\text { Gastric } \\
\text { lymphoma }\end{array}$ & $\begin{array}{l}\text { Food and suture } \\
\text { granulomas }\end{array}$ \\
\hline Viral esophagitis & Sarcoidosis & Histoplasmosis \\
\hline $\begin{array}{l}\text { Herpes simplex } \\
\text { virus }\end{array}$ & Tuberculosis & Whipple's disease \\
\hline $\begin{array}{l}\text { Epidermolysis } \\
\text { bullosa }\end{array}$ & Syphilis & $\begin{array}{l}\text { Idiopathic isolated } \\
\text { granulomatous } \\
\text { gastritis }\end{array}$ \\
\hline
\end{tabular}

asymptomatic UGI-CD. ${ }^{22}$ These findings helped clarify the diagnosis in 11 of 13 IC patients. Due to this higher prevalence and the high rate of silent UGI-CD found in this and other prospective endoscopic studies, this study concluded that UGI endoscopy should be routine in the evaluation of all pediatric patients with $C D$. Another report comparing $C D$ and UC biopsy results during EGD in pediatric patients showed a problematically high rate of histological changes in UC patients including significantly more intraepithelial lymphocytes for UC patients, emphasizing the importance of a skilled pathologist needed for the differentiation of these diseases. ${ }^{23}$ Current recommendation from the ESPGHAN Revised Porto Criteria for all children and adolescents diagnosed with IBD include EGD and ileocolonoscopy with histology and imaging of the small bowel. ${ }^{24}$

Isolated UGI manifestations of $C D$ are uncommon. One study found only $0.8 \%$ isolated UGI manifestations in a series of 877 patients with CD. ${ }^{25}$ A larger study found that $13 \%$ of 1,015 patients reviewed retrospectively from a clinical database had UGI manifestations of CD, and only $2.5 \%$ had isolated UGI disease. ${ }^{25}$ In this study, increased age at diagnosis correlated with lower rates of UGI manifestations and more predominant colonic disease. This again established an association between UGI involvement, earlier age of onset, and more aggressive overall phenotype.

Symptomatology of CD is vast; however, UGI-CD presents most commonly with upper abdominal pain, obstruction, and occasionally massive bleeding. ${ }^{21,26}$ UGI-CD is uncommonly the first sign of $C D$, and, when diagnosed, is usually synchronous with active disease elsewhere in the GI tract, most commonly ileocolic involvement. ${ }^{20}$ In addition, it generally presents as contiguous disease from the proximal jejunum and usually involves the duodenum and stomach serially. ${ }^{3}$ Treatment for $C D$ is primarily medical for acute flares and maintenance therapy; however, surgery is a cornerstone of $C D$ management for complications such as uncontrolled bleeding, perforation, fistulae, and obstruction. Surgery for $C D$ of the small bowel, colon, and rectum involves resection, strictureplasty, diversion, or a combination of these. Operating on UGICD has its own set of challenges. This is mainly due to its proximal location with limited access, and structural relationship to other key organs in the GI tract.

\section{Classification and Diagnosis of Upper Gastrointestinal IBD}

The diagnosis of IBD depends on clinical, radiographic, endoscopic, and histologic factors. Attempts to formalize the classification have been made at the Rome, Vienna, and Montreal Working Parties. ${ }^{27,28}$ The first two of these meetings created the ALB (age, location, and behavior) criteria for classification of $C D$, while the Montreal classification created finer stratification by age as well as allowing for the classification of patients with several concurrent areas of active disease. $^{27}$ UGI-CD is specified as L4 in this classification schema, and is used as a modifier to L1-L3 disease so that the classification captures all areas of disease. The L4 classification includes a large strata of the $C D$ population with 
wide ranges of disease severity in the upper GI tract and elsewhere.

Many attempts have been made to integrate serologic criteria into the diagnosis of IBD. While serologic studies can be suggestive of different disease processes, all lack sensitivity and consequently are of limited diagnostic benefit. The common serum antibodies tested in this workup include perinuclear antineutrophil cytoplasmic antibody (pANCA), anti-Saccharomyces cerevisiae antibody (ASCA), anti-outer membrane porin $\mathrm{C}$ antibody (anti-OmpC), and anti-CBir1 flagellin antibody (anti-CBir1). Combined ASCA immunoglobulin $G$ or immunoglobulin A positive and PANCA negative serology has sensitivity and specificity of 55 and $93 \%$ for $C D$, and pANCA positivity with no ASCA measurement has sensitivity and specificity for UC of 55.3 and $88.5 \%$, respectively (Reese 2006). Numerous studies have also found various serologies to suggest different patterns of $C D$ or to correlate to disease severity or need for surgery. ${ }^{29-33}$

There are no known serologies to distinguish location or UGI involvement. Serologic studies have been evaluated for their ability to determine a diagnosis in those patients labeled initially as IC. Indeterminate colitis is a variant of IBD, which does not fully fit the diagnostic picture of either CD or UC, though in many cases it eventually takes the phenotypic characteristics of either CD or UC. While serologic studies are often used to fill in a full clinical picture to suggest a clearer diagnosis, the use of EGD in cases of IC can define the disease and lead to better medical management. ${ }^{21,22}$

\section{Gastroduodenal Crohn's Disease}

The first report of duodenal CD was described by Gottlieb and Alpert in 1937, followed by Ross who reported gastric CD in 1949. ${ }^{34,35}$ Gastroduodenal Crohn's occurs in 0.5 to $4 \%$ of patients with $\mathrm{CD}$ and is most commonly associated concomitant disease in the distal small bowel and colon.,17 Yamamoto et al found that $56 \%$ of patients diagnosed with gastroduodenal $\mathrm{CD}$ had previous $\mathrm{CD}$ elsewhere in the GI tract, while in $35 \%$ of cases gastroduodenal CD was diagnosed synchronously with distant disease. ${ }^{36}$ Less than one-third of patients will have isolated gastroduodenal disease at the time of diagnosis and most will develop distal disease later in life. ${ }^{3,17}$ A study performed at the Lahey Clinic involving 89 patients showed $92 \%$ of patients with primary gastroduodenal $C D$ had developed distal disease within a follow-up of 11.7 years. ${ }^{26}$ UGI-CD is often asymptomatic and therefore is diagnosed infrequently in adults compared with pediatric patients where UGI endoscopy is performed routinely., ${ }^{411}$ However, even with UGI-CD remaining largely asymptomatic, some advocate for routine endoscopy of the upper GI tract to determine the presence and extent of UGI-CD, and to help distinguish UC from CD in cases that are difficult to diagnose based on presence of distal disease. ${ }^{15,37-39}$

Gastroduodenal CD is almost equally common in both genders with a male:female ratio of 1.2:1.,4 Adult Crohn's gastritis is usually mild and presents with inflammation, which is usually responsive to medical management. Although Crohn's gastritis occurs most commonly in adults during the third and fourth decades of life, pediatric cases have been reported. ${ }^{3,4}$ This can manifest as inflammation (gastroduodenitis), fistula, obstruction/stricture, or a combination of these.

Pediatric Crohn's gastritis is often asymptomatic and is usually diagnosed on routine endoscopy. ${ }^{4,17}$ Reports of focally enhanced gastritis (FEG) in the pediatric literature have demonstrated an association with FEG and CD and have shown limited association with UC. A retrospective study from Roka et al examined pediatric upper endoscopy in patients with CD $(n=185)$ and in patients without CD who required endoscopy for upper abdominal complaints $(n=684)$. FEG was found significantly more frequently among children with IBD than without ( 35.7 vs. $3.4 \%$, respectively, $p<0.001$ ), and all types of IBD had higher frequencies of FEG compared with non-IBD (CD $54.1 \%$, UC 21.6\%, IBD unclassified $18.4 \%, p<0.001) .{ }^{40}$ In addition, FEG had a sensitivity and specificity of 35.7 and $96.6 \%$ in distinguishing IBD from non-IBD patients and a sensitivity and specificity of 54.1 and $78.4 \%$, respectively, for discriminating CD from UC. There was, however, no correlation with the presence of FEG and lower GI IBD. ${ }^{40}$

Crohn's gastritis is the most common site of UGI-CD, being identified $50 \%$ of the time in the initial disease presentation of the upper GI tract; however, it is often clinically associated with Crohn's duodenitis and therefore often referred to as "gastroduodenal CD." 4,17 Some authors have found that the gastritis is most commonly (60\%) continual with the duodenum, starting in the gastric antrum and progressing distally to the proximal duodenum. ${ }^{17}$ Yamamoto et al described the most frequent sites of gastroduodenal involvement as duodenal bulb inflammation with or without gastric involvement, with only $28 \%$ of patients having isolated disease distal to the first part of the duodenum. ${ }^{41}$

Gastroduodenal fistulas have a slight male predominance in duodenocolic fistulas, and no gender distribution differences for gastric fistulas. Both present with abdominal pain, diarrhea, and weight loss. Feculent vomiting may be encountered secondary to gastrocolic fistulas in which the site of active Crohn's is distal disease and the duodenum/stomach is not involved primarily, that is, ileal-duodenal fistula, where only the ileal disease needs resecting, or duodenocolic fistula where patients have had previous ileocolic resections and had disease recurrence just proximal to the anastomosis leading to duodenal disease. ${ }^{3,19,42}$ Primary gastroduodenal fistulas are exceedingly rare with a reported incidence of less than $0.6 \%$, and the stomach or duodenum is likely to be involved as a target organ from a fistula originating more distally such as the terminal ileum or transverse colon. A study by Van Patter et al examining 600 patients reported a $0.3 \%$ incidence. ${ }^{3,43,44}$ Gastric fistulas usually originate from the transverse colon and typically involve the greater curvature of the stomach, while duodenal fistulas form from adjacent colon or ileocolic anastomosis to the second and third portions of the duodenum.,36,45 Treatment by takedown of the fistula, debridement, and mobilization of the stomach and/or duodenum, followed by primary repair with one or two layers, is generally sufficient; however, jejunal serosal patches have been reported as a technique. ${ }^{3}$ Wilk et al 
described duodenojejunostomy for a duodenal fistula/defect without any reported complications; however, reports from Yamamoto et al and Jacobson et al show that primary closure without tension is sufficient. ${ }^{3,45-47}$

The symptomatology of gastroduodenal CD varies and is largely dependent on any degree of obstruction present ${ }^{3,48}$. As stated previously, gastroduodenal CD is commonly asymptomatic in both the pediatric and adult literature. ${ }^{3,15,17,36,39,48}$ Many of the gastrointestinal symptoms of UGI-CD mimic peptic ulcer disease and lower GI Crohn's as nonspecific epigastric pain, nausea/vomiting, and bloating ${ }^{3}$ (-Table 2). The most common symptom in gastroduodenal $\mathrm{CD}$ in adults is epigastric abdominal pain, which is nonradiating, postprandial, and relieved by antacids and food. ${ }^{17,26}$ Nugent and Roy documented the symptoms of gastroduodenal $C D$, listed in decreasing frequency: pain, nausea, vomiting, weight loss ( $>4.5 \mathrm{~kg}$ ), melena, and fever. ${ }^{39}$ Lenaerts et al described the most common symptoms of pediatric gastroduodenal CD being dysphagia, pain with eating, nausea/vomiting, weight loss, and aphthous ulceration of the oral cavity ${ }^{48,49}$ ( - Table 3). Continued epigastric pain and/or nausea and vomiting leading to weight loss is often a sign of gastroduodenal stricture from chronic inflammation., 3,48 Perforation and acute bleeding is much more commonly associated with long-standing inflammation in peptic ulcer disease, and not in $\mathrm{CD}$. Both of these are exceedingly rare in gastroduodenal $\mathrm{CD}$, which occasionally results in chronic, nonacute bleeding leading to chronic anemia. $3,39,50$

\section{Evaluating Gastroduodenal Crohn's Disease}

Radiographic findings can suggest CD or UC in the right clinical setting. Positive findings on UGI studies are similar to

Table 2 Symptoms of gastroduodenal Crohn's disease

\begin{tabular}{|l|l|}
\hline Common symptoms & Rare symptoms \\
\hline Epigastric pain & Anemia \\
\hline Nausea/vomiting & Diarrhea \\
\hline Anorexia/weight loss & $\begin{array}{l}\text { Feculent vomiting } \\
\text { (gastrocolic fistula) }\end{array}$ \\
\hline Early satiety & Hematemesis \\
\hline Bloating & Melena \\
\hline Belching & \\
\hline
\end{tabular}

Table 3 Common presenting symptoms in gastroduodenal Crohn's disease

\begin{tabular}{|l|l|}
\hline $\begin{array}{l}\text { Adult (Nugent and Roy, } \\
\boldsymbol{n}=\mathbf{8 9} \text { ) }\end{array}$ & $\begin{array}{l}\text { Pediatric (Lenaerts et al, } \\
\boldsymbol{n}=\mathbf{6 9}\end{array}$ \\
\hline Abdominal pain & Dysphagia \\
\hline Weight loss & Pain with eating \\
\hline Nausea/vomiting & Nausea/vomiting \\
\hline Diarrhea & Weight loss \\
\hline Bleeding/anemia & Aphthous mouth ulcers \\
\hline
\end{tabular}

those found in lower GI CD, including wall thickening, stenosis, obstruction, and ulceration. Findings such as ileitis or colitis may be found on computed tomography (CT) scans or magnetic resonance imaging (MRI) studies, but are nonspecific for IBD. These imaging studies are often useful in the evaluation of patients with an acute abdomen, especially CT which is often available to clinicians in an acute setting, or in ruling out intra-abdominal abscess prior to the initiation of anti-TNF therapy initiation. Due to the chronic nature of IBD, the routine use of CT scan must be weighed for benefit against the cumulative effects of ionizing radiation in these patients.

Enterography is a useful adjunct for evaluating CD and can help diagnose and localize areas of stricturing disease throughout the GI tract. MR and CT enterography are comparably useful diagnostic tests, with the former avoiding the radiation of CT scan. Conventional fluoroscopic evaluation uses about one-third the radiation of its CT equivalent, and is more useful for disease limited to the mucosa. Gadoliniumenhanced MRI and the use of diffusion-weighted imaging may also provide some advantage in the differentiation of fibrotic strictures and acute inflammation. ${ }^{51-54}$

The first pathology noted on double-contrast imaging are aphthous ulcerations, followed by thickened rugal folds, cobblestoning, pseudodiverticula, and strictures-evident by a tubularization of the antrum, pylorus, and duodenum. ${ }^{3,19}$ This scarring is secondary to chronic fibrosis, and resembles a gastroduodenostomy for ulcer disease and coining the term "pseudo-Billroth 1 appearance." 3,11,17,55 A "ram's horn" sign is rare, but representative on contrast imaging for antral and duodenal bulb disease. ${ }^{3,17,38,56}$ Upper GI studies may also elucidate fistulas with the distal small bowel and/or colon.

Though endoscopy can be essential to correct diagnosis of UGI symptoms in CD, its use may be limited in patients with acute abdomen. Diagnostic EGD in CD patients has 60 to $70 \%$ rate of positive findings, and some authors advocate screening EGD in all CD patients. ${ }^{20,57}$ Screening EGD is recommended for pediatric patients with $C D$, as the rate of UGI-CD is higher in this population and the presence of disease on EGD may have implications regarding disease severity and need for operation. ${ }^{13,14}$

Endoscopically, Crohn's gastritis can produce a range of morphologic features both microscopically and macroscopically, but most commonly it is identified as superficial, mild, and diffuse inflammation (- Table 4)., ${ }^{45}$ A summary of the locations and types of $C D$-related changes commonly seen on EGD can be seen in -Fig. 1. The Montreal classification

Table 4 Endoscopic findings in gastroduodenal Crohn's disease

\begin{tabular}{|l|l|}
\hline Edema & Erythema \\
\hline Friability & Granularity \\
\hline Erosions & Aphthous ulcers \\
\hline Thickened folds & Mucosal nodularity/cobblestoning \\
\hline Strictures & Fistulae \\
\hline Pseudodiverticula & Luminal narrowing \\
\hline
\end{tabular}




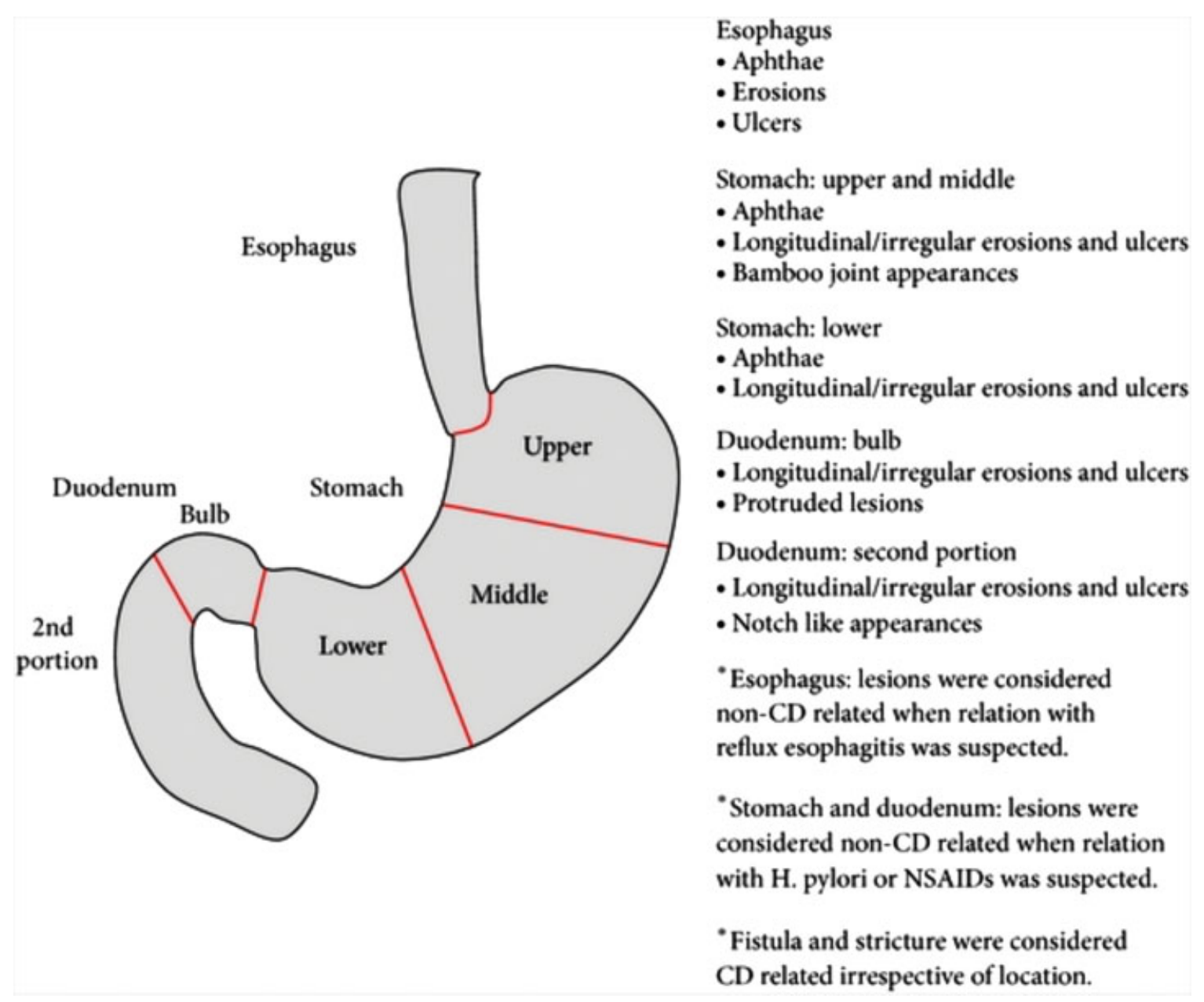

Fig. 1 Manifestations of CD seen on EGD. (https://www.hindawi.com/journals/bmri/2014/610767/fig1/). ${ }^{20}$

defined microscopic features as focal-enhanced gastritis, focal crypt irregularity/crypt distortion, fissural ulceration and/or granulomas sans $H$. pylori infection, and macroscopic findings as erosions, aphthous lesions, ulcerations, and strictures. ${ }^{15,27}$

Crohn's gastritis can display evidence of neutrophilic epithelial clusters termed "focally enhanced gastritis," aphthoid ulcers, and noncaseating granulomas. ${ }^{4}$ It can also mimic the appearance of $H$. pylori infection and other classic signs and symptoms of peptic ulcer disease in both endoscopic and clinical findings. ${ }^{3}$ H. Pylori rates in the $\mathrm{CD}$ patient population are lower than that in the general population, possibly as a result of the regular antibiotic administration in this population..$^{57,58}$

Despite this, the testing of $H$. Pylori during EGD done for foregut complaints is still recommended, as the presence of this infection can cause concomitant inflammation with $C D$ and a positive finding requires standard antibiotic treatment. Less commonly, duodenal CD can present with bleeding, pancreatitis, or common bile duct obstruction.,37,50,59-62 In their series of $C D$ patients who underwent EGD, Sakuraba et al found evidence of $\mathrm{CD}$ changes in the duodenal bulb of $32 \%$ of patients and the second portion of the duodenum in $18 \%$ of patients. $^{20}$
Recent studies have shown that although UGI inflammation associated with IBD was classically defined as UGI-CD, UC displays morphologic changes in the upper GI tract as well. ${ }^{4}$ It is therefore necessary to distinguish between $\mathrm{CD}$ and UC and their treatment algorithms will differ.

Nugent and Roy established criteria to diagnose UGI-CD specifically, which consisted of one of the following two criteria: (1) on pathology, the finding of noncaseating granulomatous inflammation of the duodenum with or without coexisting $\mathrm{CD}$ at other gastrointestinal tracts sites, and without an alternative systemic granulomatous disorder, or (2) clearly documented $\mathrm{CD}$ as another gastrointestinal site and radiologic and/or endoscopic evidence of diffuse inflammatory changes suggestive of $C D .^{39,48}$ The finding of a bamboo joint-like appearance in the stomach, characterized by longitudinal inflamed folds with perpendicular erosions and linear furrows, is also pathognomonic for $\mathrm{CD}{ }^{63}$ This finding, while relatively recognizable to endoscopists' various skill levels, does not seem to correlate significantly with disease severity. Endoscopic erosions are rare in UC, while granulomas are diagnostic of CD and not seen in UC. Aphthoid erosions and mild inflammation that infiltrates gastric glands are also classically associated with $\mathrm{CD}$ and not a feature of UC-related inflammation, so much so that if $\mathrm{CD}$ is ruled out, non-IBD 
differentials like peptic ulcer disease and malignancy should be explored. ${ }^{4}$ Diffuse chronic duodenitis can be found in patients who had undergone colectomy with pouch reconstruction and suffered from pouchitis. ${ }^{64}$

Furthermore, the presence of duodenitis may be predictive of pouchitis in UC patients, especially occurring shortly after total colectomy is performed. This association has been reported in several other cases as well, and in most reports both the duodenitis and pouchitis are readily treated with medical therapy alone. ${ }^{65-67}$ - Table 2 lists typical findings of gastroduodenal CD on endoscopy. Neoplasms may appear as $\mathrm{CD}$ and must be ruled out, as well as linitis plastica, lymphoma, and locally advanced T4 tumors of the upper GI tract invading the gastroduodenum.

\section{Medical Management of Gastroduodenal Crohn's Disease}

Gastroduodenal CD is initially managed medically, if possible, paralleling the treatment of $C D$ elsewhere in the GI tract. A step-wise treatment approach is generally used, where more powerful immunosuppressive agents are added only if the patient progresses through treatment. ${ }^{19}$ Juxtapose to a step-wise approach, a top-down approach has been popularized since biologic therapy was added to the armamentarium of IBD treatment. Top-down medical treatment involves initially starting the patient on immunosuppressants and biologics and de-escalating medications as the patient improves; this has led to decreased rates of hospitalizations and operative intervention, however, exposes the patients to overtreatment. ${ }^{68}$ For UGI-CD, antacids, with either histamine $\left(\mathrm{H}_{2}\right)$ blockers or proton pump inhibitors, are a mainstay of treatment, especially while working up differentials such as gastritis, gastroesophageal reflux disease, or peptic ulcer disease. ${ }^{3,69}$ Antacids may not confer histologic evidence of improvement; however, they do provide symptomatic relief and limit further mucosal damage by gastric acid on possible gastroduodenal CD. ${ }^{19,69,70}$ Next, if necessary, treating $H$. pylori is paramount once its presence and eventual eradication is confirmed.

Though data are scarce on its relationship to UGI-CD symptoms, most patients are treated with standard $C D$ regimens such as 5-aminosalicylic acid, azathioprine, 6mercaptopurine, methotrexate, and steroids. ${ }^{3}$ The pro-drug sulfasalazine is not active until in the distal ileum or colon, when it is active in the form 5-aminosalicyclic acid, and therefore will have limited used in upper GI disease. Mesalamine is $\mathrm{pH}$ dependent and although a slow-release formula called Pentasa is released in the proximal small bowel, its major absorption will be distal to UGI-CD. ${ }^{69}$ Although Korelitz et al in 1993 reported marked improvement or complete healing in $100 \%$ of patients with nonsteroid therapy, the exact combination for medically induced remission of UGI$\mathrm{CD}$ is not known and must be tailored to each patient; however, steroids do appear to confer a durable clinical response. ${ }^{71}$ Griffiths et al reported a moderate clinical response in 10 patients with gastroduodenal disease treated with oral corticosteroids along with 6-mercaptopurine and
$\mathrm{H}_{2}$-receptor blockers in 1 and 3 patients, respectively. ${ }^{72}$ Nugent and Roy reported an excellent response in $91 \%$ of patients treated with steroids for nonobstructing gastroduodenal disease; however, some were also being treated with sulfasalazine, $\mathrm{H}_{2}$-blockade, azathioprine, or metronidazole. ${ }^{26}$ Even with moderate to excellent clinical responses with steroids, the presence of obstruction is usually a prognostic sign that operative intervention will be needed. $3,19,46,73$ If patients continue to display symptoms while on steroid treatment, or require maintenance therapy, the immunomodulators azathioprine and 6-mercaptopurine can be used as adjuncts, but the evidence supporting this treatment is limited and anecdotal. ${ }^{69}$ In a subgroup analyzed from a 20-year experience by Korelitz et al, they reported complete therapeutic goal achievement in healing or marked improvement in patients with gastroduodenal disease treated with 6-mercaptopurine. ${ }^{71}$ Miehsler et al showed that in 12 patients with gastroduodenal $C D$ treated with prednisone and azathioprine, the prednisone could be discontinued in over half of them ( $n=7)$ after 4 to 6 months. ${ }^{74}$

The role of infliximab on gastroduodenal CD is not defined, as only small studies have shown any success, even though its use in distal CD has been well established. ${ }^{75,76}$ Kawachiya et al have the largest series, consisting of three patients all treated with infliximab for gastroduodenal CD; two patients had ileocolic disease as well. ${ }^{77}$ Their patients not only had symptomatic relief but also had evidence of macroscopic healing without any adverse effects, suggesting that infliximab treatment for gastroduodenal CD is safe, effective, and may obviate the need for invasive interventions. Firth et al published a report of a case of severe gastroduodenal disease with diffuse thickening and ulceration that responded to infliximab therapy, while Grübel et al showed resolution in one patient treated with infliximab, while a different patient with gastroduodenal disease was a nonresponder. ${ }^{75,76}$

Prior to considering surgery, endoscopic intervention can be used to treat fibrotic strictures of gastroduodenal outflow. As stated previously, obstructive features with gastroduodenal $\mathrm{CD}$ are associated with high failure rates of medical management; however, advancements in endoscopic therapy have alleviated the need for surgery in some instances. Endoscopic balloon dilation has been shown to provide durable relief in several studies. Lower GI stent deployment has been described to stent across a fibrotic stenotic segment of bowel. ${ }^{48,78-80}$ However, it has not been studied for UGI Crohn's lesions. ${ }^{80}$ Murthy successfully treated a case of gastric outlet obstruction secondary to gastroduodenal $C D$, in which three endoscopic hydrostatic dilations were performed over a 3-year period and yielded symptomatic relief for over 2 years at a time. ${ }^{78}$ Matsui et al treated five patients with balloon endoscopic dilation in a regimen that included multiple dilations within a few weeks' period, in which each session involved multiple dilations using 10-, 12-, 15-, 18- and 20-mm balloons. ${ }^{79}$ Sixty percent of their patients had recurrent symptoms within a 3.4-year follow-up; however, all were able to avoid surgery. Rana et al reported success with dilatation with intralesional steroid (triamcinolone $80 \mathrm{mg}$ ) injection in a patient who could not receive immunomodulators due to pulmonary tuberculosis. ${ }^{81}$ 
In all cases of $C D$, especially those with obstruction, timely nutritional assessment and supplementation can be critical to the patient's outcome. Elemental enteral nutrition (EEN) has been shown to induce anti-inflammatory effects in small bowel $C D$, and can prolong remission in those able to tolerate it. The use of nasojejunally administered EEN has been studied for use in inducing remission in children and was found in an early study to be equally efficacious to high-dose steroids with better weight gain profile during treatment, and subsequent studies have confirmed the efficacy of this treatment. $^{82}$

This effect was reported to be especially successful for pediatric patients with UGI-CD. ${ }^{83}$

The most recent introduction of polymeric formula EEN was found to have a more palatable flavor, allowing for the avoidance of nasojejunal feeds in some patients. Similar studies in adults have shown less impressive results, though a significant part of this may be due to poor compliance. ${ }^{84,85}$

While enteral nutrition is ideal and provides manifold benefits with a lower risk profile, some selected situations still require the administration of total parenteral nutrition (TPN). Proximal enterocutaneous or enteroenteric fistulas, short bowel syndrome, and certain cases of obstruction which are not immediately amenable to surgical treatment may require TPN. While TPN is certainly more expensive than typical enteral nutrition, certain formulations of EEN may be comparably expensive. Nevertheless, the long-term sequelae of TPN administration include high risk of Central LineAssociated Bloodstream Infection (CLABSI), liver disease, and central access complications; therefore, all attempts to maintain adequate enteral nutrition should be made. Though medical and surgical management has seen tremendous advancements as the disease has been extensively studied, the idiopathic chronic nature of $\mathrm{CD}$ remains largely unpredictable and a treatment challenge.

\section{Surgical Management for Gastroduodenal Crohn's Disease}

Surgical management for gastroduodenal CD remains the only option for patients with ongoing symptoms, mainly obstruction, fistula, or pain. ${ }^{18}$ The most common indications for operative intervention in gastroduodenal $C D$ are gastric outlet obstruction (83\%), refractory pain (11\%), and bleeding $(5 \%)^{3}$ (-Table 5). Many surgical procedures have been described, all with various outcomes and side effects; however, historically gastrojejunostomy with vagotomy is the most popular procedure performed. ${ }^{86}$ Antiulcer procedures such as antrectomy, vagotomy and Billroth I or II reconstruction, gastroenterostomy with or without vagotomy, gastroduodenostomy, duodenojejunostomy, strictureplasty, and, more recently, laparoscopic approaches to these procedures have been described. ${ }^{3,87,88}$ Murray et al highlight the safety of bypass procedures such as gastrojejunostomy, duodenojejunostomy, and gastroduodenostomy, over gastric and duodenal resection. They report low morbidity, though one-third of their patients required reoperation for marginal ulcer or reobstruction. ${ }^{19}$ Routine vagotomy should not be
Table 5 Indications for operation in gastroduodenal Crohn's disease

\begin{tabular}{|l|l|l|l|l|}
\hline Publications & Obstruction & Pain & Bleeding & Other \\
\hline $\begin{array}{l}\text { Worsey et al } \\
(n=34)\end{array}$ & 32 & 1 & 0 & 1 \\
\hline $\begin{array}{l}\text { Nugent and Roy } \\
(n=33)\end{array}$ & 23 & 9 & 1 & 0 \\
\hline $\begin{array}{l}\text { Yamamoto et al } \\
(n=23)\end{array}$ & 23 & 0 & 0 & 0 \\
\hline $\begin{array}{l}\text { Murray et al } \\
(n=22)\end{array}$ & 17 & 4 & 1 & 0 \\
\hline $\begin{array}{l}\text { Farmer et al } \\
(n=10)\end{array}$ & 7 & 2 & 1 & 0 \\
\hline
\end{tabular}

employed with all bypass procedures according to Nugent and Roy. ${ }^{39}$ Murray et al concluded that this decision must be individualized and likely avoided in CD patients with chronic severe diarrhea, significantly decreased small bowel length, or resection of the ileocecal valve. ${ }^{19}$

Resection is complicated with high morbidity, and difficulty with wide kocherization of the duodenum in the setting of a chronically inflamed retroperitoneal duodenum. These concerns led to surgeons exploring strictureplasty. Being able to find healthy, noninflamed, jejunum can also present a challenge for gastro- or duodenojejunostomy, and in that case, strictureplasty is preferable. Lastly, concerns with malignancy in bypassed segments resulting from chronic inflammation or blind loop syndrome in the bypassed limb were all reasons strictureplasty was attempted initially for gastric outlet obstruction. ${ }^{3}$

Strictureplasty also remains an effective option for obstructing duodenal disease, but mixed success has been reported. It is advocated by Worsey et al who treated 34 patients with 37 strictures. ${ }^{86}$ Overall, 21 patients had bypass procedures and 13 had strictureplasty, with the two groups having a mean follow-up of 8 and 3.5 years; respectively. Reoperation rates were similar in both groups: 2 out of 13 or $15 \%$ in the strictureplasty group, and 2 out of 21 or $10 \%$ in the bypass group. The authors decided to perform strictureplasty over bypass whenever possible, as marginal ulceration, dumping syndrome, and delayed gastric emptying (only in the bypass group) were higher in the bypass group. However, $100 \%$ of patients in both groups described symptomatic improvement and had durable results. ${ }^{86}$

Yamamoto et al retrospectively reviewed 13 patients who underwent strictureplasty (and 4 patients who underwent pyloroplasty) for obstructive duodenal CD. ${ }^{41}$ Two patients developed anastomotic dehiscence and were treated with Roux-en-Y bypass, while one patient had prolonged obstruction and eventually required gastrojejunostomy. Later on, six patients developed repeat strictures and of those six, five required repeat strictureplasty and one required duodenojejunostomy. Overall, nine out of thirteen patients needed reoperation after strictureplasty. This led to the conclusion that strictureplasty for duodenal CD is fraught with a high incidence of postoperative complications and restricture 
compared with bypass. ${ }^{46,87}$ Because the literature is so limited and retrospective, there is no clear consensus on which operation is superior. ${ }^{3,46,86}$

Campbell et al performed a meta-analysis comparing conventional (Heineke-Mikulicz and Finney) strictureplasty against several nonconventional options (modified Finney, combined Heineke-Mikulicz and Finney, modified HeinekeMikulicz, and Michelassi) and found the modified options to generally provide lower rates of immediate and delayed complications. ${ }^{89}$ Consideration of alternate configurations should be part of the preoperative planning for complex strictureplasty. Sampietro et al noted that L4 disease can be amenable to nonconventional strictureplasty in their case, and showed that recurrence in this group is comparable to that of L1 and L3 disease. ${ }^{90}$

Laparoscopic bypass with gastrojejunostomy has been described by Salky who reported 12 patients who underwent laparoscopic gastrojejunostomy, with two undergoing concomitant laparoscopic ileocolic resection for stenotic ileal disease. ${ }^{87}$ Eleven patients had resolution of symptoms and durability over 4.2 years. One patient had an anastomotic mechanical failure that required reoperation. They reported improved cosmetic result and shorter hospital length of stay, with no other morbidity or mortality. ${ }^{69,87}$

Dysfunction of the ampulla with resultant pancreatitis and cholangitis has been reported in several series of $C D$ patients. $^{91-93}$ Treatments for this disease process may involve medical treatment of $\mathrm{CD}$ and endoscopic stent placement. In some cases, a pancreaticoduodenectomy may be necessary to provide unimpeded biliary flow and prevent repeated incidents of pancreatitis. ${ }^{70,91}$ While reports of pancreaticoduodenectomy are available with good outcome, less morbid interventions should be sought if possible. ${ }^{94-96}$

\section{Crohn's Disease of the Esophagus}

Esophageal $\mathrm{CD}$ is the rarest form of foregut $\mathrm{CD}$ involvement first described by Franklin and Taylor in 1950, and congruently, there are limited literature and data regarding this entity. ${ }^{48,97}$ A large Mayo Clinic article examining 12,367 patient charts over 20 years found only 24 patients with esophageal $C D(0.12 \%) .{ }^{98}$ As with gastroduodenal $C D$, there are disparities in the incidence of esophageal $C D$ described between adult and pediatric patient populations, largely explained by the routine use of upper endoscopy in the adolescent population. ${ }^{98}$ The incidence and prevalence of esophageal CD reported in adults is 1.2 to $1.8 \%$ and 3.3 to $6.8 \%$, respectively, with pediatric incidence and prevalence being 25.8 to $41.5 \%$ and 7.6 to $17.6 \%$, respectively. ${ }^{98-102}$ The prevalence in adolescent patients is reported to range between 33 and $43 \%{ }^{99,101}$

The challenges of diagnosing and reporting Crohn's esophagitis exist for two mains reasons: first, esophageal CD resembles symptoms as erosive esophagitis or acid reflux; and second, the nonspecific histologic findings make esophageal CD difficult to distinguish (-Table 1). The most common symptoms of Crohn's esophagitis are reported by De Felice et al, and include dysphagia (54\%), odynophagia
(33\%), epigastric pain (33\%), acid reflux (25\%), and chest pain $(13 \%) .{ }^{98}$ Again, diagnosis is challenging as many of these symptoms are indistinguishable from acid reflux or pillinduced contact ulcers. ${ }^{3,4}$ Occasionally, patients initially present with advanced disease, presenting with fistulas, progressive dysphagia, and strictures secondary to chronic inflammation. The median time between $\mathrm{CD}$ diagnosis and esophageal involvement is reported to be 3 years; however, in cases where upper endoscopy was performed during the initial diagnosis of $\mathrm{CD}, 43 \%$ of patients had evidence of esophageal $C D$ at that time. ${ }^{98}$ Twenty-one percent of patients who were diagnosed with esophageal CD also had synchronous gastroduodenal and ileocolic disease. There is also an association with oral ulcers, as 33\% of patients with esophageal CD symptoms had evidence of oral ulcers of exam. ${ }^{98}$

Endoscopy correlates with esophagus-specific symptoms, such as ulcerations, strictures, and fistulas, which were signs of advanced disease and seen in the majority of patients reported by De Felice et al. ${ }^{98}$ While granulomas are not frequently seen, with some reports describing granulomas in 0 to $21 \%$ of patients, aphthoid ulcers found in the setting of active inflammation are typically greater than what is seen with Crohn's gastritis. $4,48,98,102$

Authors have described the stages of esophageal CD based on endoscopy findings. The earlier stage consists of erythema, edema, aphthous ulcers, and granularity of the esophageal mucosa. ${ }^{48}$ The second, or advanced stage, consists of stricturing and stenosis, as stenosis is typically $1 \mathrm{~cm}$ in length or greater. ${ }^{48}$ De Felice et al reported the most common locations of esophageal involvement were $29 \%$ midand distal esophagus, $17 \%$ mid-distal, $21 \%$ diffuse involvement, and $4 \%$ proximal disease. ${ }^{98}$ Though only two patients had fistulizing disease and four patients had strictures, 75\% of patients had inflammatory esophageal CD. Erythema and erosions were present half of the time, deep ulcerations in $13 \%$, and pseudopolyps in $4 \%{ }^{98}$ Histology may also show "squiggle cells" which are dense intraepithelial lymphocytes which are not specific for $C D$, as celiac disease and reflux esophagitis share this feature. Eosinophilic esophagitis may also be present and is only distinguishable from Crohn'srelated esophagitis by the pathologic Th1-type response typical of $C D$ as opposed to the Th2-type response in eosinophilic esophagitis. ${ }^{4}$ Though UC esophagitis shares features of $C D$ with increased eosinophils, deep ulcerations and granulomas are not present with UC.

\section{Medical Treatment of Crohn's Esophagitis}

The medical treatment of esophageal $C D$ is analogous to gastroduodenal $\mathrm{CD}$. As in gastroduodenal $\mathrm{CD}$, a stepwise approach to multidrug therapy is usually needed; however, there are no long-term data on the optimal regimen. Most patients with esophageal $C D$ have distal disease and are likely on maintenance therapy by the time they are diagnosed with esophageal CD; however, the addition of antacids (either $\mathrm{H}_{2}$ blockade or proton pump inhibitors), steroids, and 5-aminosalicylates are considered first-line treatment once esophageal disease is identified., ${ }^{3,48}$ Although esophageal 
disease can be devastating, in the form of esophageal fistulas, the majority of patients are treated medically without the need for endoscopic or surgical intervention. ${ }^{98}$ Many immunomodulars are available as previously described, but many of them have low activity in the upper GI tract and therefore steroids appear to have the greatest reported effect on longterm remission. ${ }^{103}$ D'Haens et al followed up 14 patients for 83 patient-years and found that $75 \%$ of patients responded well to steroid treatment. ${ }^{104}$ The same was true for De Felice et al who treated nine patients with steroids, having seven responding completely and one patient have a partial resolution over an average of 3 months. Two became steroid dependent. ${ }^{98}$ The swallowing of aerosolized budesonide, which is employed for the treatment of eosinophilic esophagitis, has also been shown to successfully treat esophageal CD with a "topical" approach which could minimize systemic steroid absorption. ${ }^{98,105}$

Infliximab therapy has seen favorable results, even in patients who failed previous therapies. ${ }^{98}$ In a series from De Felice et al, infliximab resulted in complete resolution in their cohort of five patients. Two additional patients were treated with infliximab after prednisone induction therapy without any documented recurrence. Infliximab was also shown to be effective in fistulizing esophageal $C D$, as an esophageal gastric fistula was successfully closed with follow-up endoscopy.

\section{Surgical Treatment of Esophageal Crohn's Disease}

Surgery for esophageal CD is indicated for esophageal stenosis, obstruction, ulcerations, fistula, or malignancy. ${ }^{3}$ For stenotic lesions, advanced endoscopy with bougie or balloon dilatation has been effective and can delay or obviate the need for surgical intervention. ${ }^{48,106}$ Stenotic lesions can also be managed with electrosurgical division under direct endoscopy for symptom relief. ${ }^{48,107}$ Mathis et al described an esophageal CD stricture dilatation with concomitant fibrin sealant to manage an esophago-bronchial fistula with stricture for over 18 months. ${ }^{108}$ There are no reports of intralesional steroid injection in esophageal CD patients in isolation; however, De Felice et al treated patients with combinations of dilatation, biologics, dapsone, steroid injections, steroid gel, and proton pump inhibitors. ${ }^{48}$ If ulceration forbids advanced endoscopic therapy, systemic treatment in combination with gastrostomy, either percutaneous or open, may allow the ulcer to heal while still giving enteral nutritional support. ${ }^{48,109}$ Stenting is also a therapeutic option but has not been widely studied.

Uncommonly, through case reports, esophageal CD can lead to fistulous formation to the tracheobronchial tree and mediastinum leading to complications such as airway issues, pneumonias, paraesophageal abscess, and mediastinitis. ${ }^{110,111}$ Past reports have examined esophagectomy in the setting of Crohn's esophagitis with fistula or obstruction, or to rule out malignancy. 3,112 These reports showed a $25 \%$ mortality rate, which is similar to another report by Rholl et al where two out of five patients operated on for esophageal airway fistula died after esophagectomy. ${ }^{113}$

\section{Conclusion}

UGI-CD remains a rare aspect of the disease. Routine screening in the pediatric population has demonstrated a higher prevalence; however, it is likely under-reported in the adult population. Many adults remain asymptomatic, possibly because they are being treated for distal disease a priori. For the patients who are symptomatic, it will usually improve with medical management, the best results being with use of steroids, and more recently with biologic agents. Though most patients respond to medical therapy, if surgical intervention is needed for gastroduodenal disease it is primarily for obstruction secondary to stricture formation, perforation, or bleeding. Strictureplasty and bypass are both options with comparable morbidity, although bypass has higher reported rates of dumping syndrome and marginal ulceration. Cases of gastroduodenal fistulous disease from active distal disease may involve the stomach or duodenum and are usually managed surgically. Esophageal CD is exceptionally rare, is usually inflammatory, and mainly managed medically, but in severe cases can fistulize to surrounding structures in the mediastinum which may require the highly morbid esophagectomy.

\section{References}

1 Comfort MW, Weber HM, Baggenstoss AH, Kiely WF. Nonspecific granulomatous inflammation of the stomach and duodenum; its relation to regional enteritis. Am J Med Sci 1950;220(06): 616-632

2 Crohn BB, Ginzburg L, Oppenheimer GD. Landmark article Oct 15, 1932. Regional ileitis. A pathological and clinical entity. By Burril B. Crohn, Leon Ginzburg, and Gordon D. Oppenheimer. JAMA 1984;251(01):73-79

3 Reynolds HL Jr, Stellato TA. Crohn's disease of the foregut. Surg Clin North Am 2001;81(01):117-135, viii

4 Goldstein NS, Lewin KJ, Doty JE. Gastrointestinal tract. Pathology (Phila) 1996;3(02):349-365

5 Loftus EV Jr, Schoenfeld P, Sandborn WJ. The epidemiology and natural history of Crohn's disease in population-based patient cohorts from North America: a systematic review. Aliment Pharmacol Ther 2002;16(01):51-60

6 Loftus EV Jr. Update on the incidence and prevalence of inflammatory bowel disease in the United States. Gastroenterol Hepatol (N Y) 2016;12(11):704-707

7 Bousvaros A, Antonioli DA, Colletti RB, et al; North American Society for Pediatric Gastroenterology, Hepatology, and Nutrition; Colitis Foundation of America. Differentiating ulcerative colitis from Crohn disease in children and young adults: report of a working group of the North American Society for Pediatric Gastroenterology, Hepatology, and Nutrition and the Crohn's and Colitis Foundation of America. J Pediatr Gastroenterol Nutr 2007;44(05):653-674

8 Kappelman MD, Rifas-Shiman SL, Kleinman K, et al. The prevalence and geographic distribution of Crohn's disease and ulcerative colitis in the United States. Clin Gastroenterol Hepatol 2007;5(12):1424-1429

9 Sandler RS, Everhart JE, Donowitz M, et al. The burden of selected digestive diseases in the United States. Gastroenterology 2002; 122(05):1500-1511

10 Goodhand J, Dawson R, Hefferon M, et al. Inflammatory bowel disease in young people: the case for transitional clinics. Inflamm Bowel Dis 2010;16(06):947-952 
11 Wagtmans MJ, Verspaget HW, Lamers CB, van Hogezand RA. Clinical aspects of Crohn's disease of the upper gastrointestinal tract: a comparison with distal Crohn's disease. Am J Gastroenterol 1997;92(09):1467-1471

12 Aloi M, Lionetti P, Barabino A, et al; SIGENP IBD Group. Phenotype and disease course of early-onset pediatric inflammatory bowel disease. Inflamm Bowel Dis 2014;20(04):597-605

13 Ammoury RF, Pfefferkorn MD. Significance of esophageal Crohn disease in children. J Pediatr Gastroenterol Nutr 2011;52(03): 291-294

14 Renault M, Goodier A, Subramony C, Hood B, Bishop P, Nowicki $M$. Age-related differences in granulomatous gastritis: a retrospective, clinicopathological analysis. J Clin Pathol 2010;63(04): 347-350

15 Horjus Talabur Horje CS, Meijer J, Rovers L, van Lochem EG, Groenen MJM, Wahab PJ. Prevalence of upper gastrointestinal lesions at primary diagnosis in adults with inflammatory bowel disease. Inflamm Bowel Dis 2016;22(08):1896-1901

16 Alcántara M, Rodriguez R, Potenciano JL, Carrobles JL, Muñoz C, Gomez R. Endoscopic and bioptic findings in the upper gastrointestinal tract in patients with Crohn's disease. Endoscopy 1993;25(04):282-286

17 Kefalas CH. Gastroduodenal Crohn's disease. Proc (Bayl Univ Med Cent) 2003;16(02):147-151

18 Song X-M, Gao X, Li M-Z, et al. Clinical features and risk factors for primary surgery in 205 patients with Crohn's disease: analysis of a South China cohort. Dis Colon Rectum 2011;54(09): 1147-1154

19 Murray JJ, Schoetz DJ Jr, Nugent FW, Coller JA, Veidenheimer MC Surgical management of Crohn's disease involving the duodenum. Am J Surg 1984;147(01):58-65

20 Sakuraba A, Iwao Y, Matsuoka K, et al. Endoscopic and pathologic changes of the upper gastrointestinal tract in Crohn's disease. BioMed Res Int 2014;2014(03):610767-6

21 Ueno F, Matsui T, Matsumoto T, Matsuoka K, Watanabe M, Hibi T; Guidelines Project Group of the Research Group of Intractable Inflammatory Bowel Disease subsidized by the Ministry of Health, Labour and Welfare of Japan and the Guidelines Committee of the Japanese Society of Gastroenterology. Evidencebased clinical practice guidelines for Crohn's disease, integrated with formal consensus of experts in Japan. J Gastroenterol 2013; 48(01):31-72

22 Castellaneta SP, Afzal NA, Greenberg M, et al. Diagnostic role of upper gastrointestinal endoscopy in pediatric inflammatory bowel disease. J Pediatr Gastroenterol Nutr 2004;39(03): 257-261

23 Tobin JM, Sinha B, Ramani P, Saleh AR, Murphy MS. Upper gastrointestinal mucosal disease in pediatric Crohn disease and ulcerative colitis: a blinded, controlled study. J Pediatr Gastroenterol Nutr 2001;32(04):443-448

24 Levine YY, Koletzko J, Turner D. ESPGHAN revised Porto criteria for the diagnosis of inflammatory bowel disease in children and adolescents [in Chinese]. Zhonghua Er Ke Za Zhi 2016;54(10): 728-732

25 Freeman HJ. Application of the Vienna Classification for Crohn's disease to a single clinician database of 877 patients. Can J Gastroenterol 2001;15(02):89-93

26 Nugent FW, Richmond M, Park SK. Crohn's disease of the duodenum. Gut 1977;18(02):115-120

27 Satsangi J, Silverberg MS, Vermeire S, Colombel JF. The Montreal classification of inflammatory bowel disease: controversies, consensus, and implications. Gut 2006;55(06):749-753

28 Gasche C, Scholmerich J, Brynskov J, et al. A simple classification of Crohn's disease: report of the Working Party for the World Congresses of Gastroenterology, Vienna 1998. Inflamm Bowel Dis 2000;6(01):8-15

29 Arnott IDR, Landers CJ, Nimmo EJ, et al. Sero-reactivity to microbial components in Crohn's disease is associated with disease severity and progression, but not NOD2/CARD15 genotype. Am J Gastroenterol 2004;99(12):2376-2384

30 Forcione DG, Rosen MJ, Kisiel JB, Sands BE. Anti-Saccharomyces cerevisiae antibody (ASCA) positivity is associated with increased risk for early surgery in Crohn's disease. Gut 2004; 53(08):1117-1122

31 Ferrante M, Henckaerts L, Joossens M, et al. New serological markers in inflammatory bowel disease are associated with complicated disease behaviour. Gut 2007;56(10):1394-1403

32 Vasiliauskas EA, Kam LY, Karp LC, Gaiennie J, Yang H, Targan SR. Marker antibody expression stratifies Crohn's disease into immunologically homogeneous subgroups with distinct clinical characteristics. Gut 2000;47(04):487-496

33 Papp M, Altorjay I, Dotan N, et al; Hungarian IBD Study Group. New serological markers for inflammatory bowel disease are associated with earlier age at onset, complicated disease behavior, risk for surgery, and NOD2/CARD15 genotype in a Hungarian IBD cohort. Am J Gastroenterol 2008;103(03):665-681

34 Gottlieb C, Alpert S. Regional jejunitis. AJR Am J Roentgenol 1937;38:881-883

35 Ross TM, Fazio VW, Farmer RG. Long-term results of surgical treatment for Crohn's disease of the duodenum. Ann Surg 1983; 197(04):399-406

36 YamamotoT, Bain IM, Connolly AB, Keighley MR. Gastroduodenal fistulas in Crohn's disease: clinical features and management. Dis Colon Rectum 1998;41(10):1287-1292

37 Turner D, Griffiths AM. Esophageal, gastric, and duodenal manifestations of IBD and the role of upper endoscopy in IBD diagnosis. Curr Gastroenterol Rep 2009;11(03):234-237

38 Rutgeerts P, Onette E, Vantrappen G, Geboes K, Broeckaert L, Talloen L. Crohn's disease of the stomach and duodenum: a clinical study with emphasis on the value of endoscopy and endoscopic biopsies. Endoscopy 1980;12(06):288-294

39 Nugent FW, Roy MA. Duodenal Crohn's disease: an analysis of 89 cases. Am J Gastroenterol 1989;84(03):249-254

40 Roka K, Roma E, Stefanaki K, Panayotou I, Kopsidas G, Chouliaras $G$. The value of focally enhanced gastritis in the diagnosis of pediatric inflammatory bowel diseases. J Crohn's Colitis 2013;7 (10):797-802

41 Yamamoto T, Bain IM, Connolly AB, Allan RN, Keighley MR. Outcome of strictureplasty for duodenal Crohn's disease. $\mathrm{Br}$ J Surg 1999;86(02):259-262

42 Pichney LS, Fantry GT, Graham SM. Gastrocolic and duodenocolic fistulas in Crohn's disease. J Clin Gastroenterol 1992;15(03): 205-211

43 Van Patter WN, Bargen JA, Dockerty MB, Feldman WH, Mayo CW, Waugh JM. Regional enteritis. Gastroenterology 1954;26(03):347-450

44 Greenstein AJ, Present DH, Sachar DB, et al. Gastric fistulas in Crohn's disease. Report of cases. Dis Colon Rectum 1989;32(10): 888-892

45 Wilk PJ, Fazio V, Turnbull RB Jr. The dilemma of Crohn's disease: ileosigmoidal fistula complicating Crohn's disease. Dis Colon Rectum 1977;20(05):387-392

46 Yamamoto T, Fazio VW, Tekkis PP. Safety and efficacy of strictureplasty for Crohn's disease: a systematic review and metaanalysis. Dis Colon Rectum 2007;50(11):1968-1986

47 Jacobson IM, Schapiro RH, Warshaw AL. Gastric and duodenal fistulas in Crohn's disease. Gastroenterology 1985;89(06): 1347-1352

48 Isaacs KL. Upper gastrointestinal tract endoscopy in inflammatory bowel disease. Gastrointest Endosc Clin N Am 2002;12(03): 451-462, vii

49 Lenaerts C, Roy CC, Vaillancourt M, Weber AM, Morin CL, Seidman E. High incidence of upper gastrointestinal tract involvement in children with Crohn disease. Pediatrics 1989;83(05):777-781

50 Podugu A, Tandon K, Castro FJ. Crohn's disease presenting as acute gastrointestinal hemorrhage. World J Gastroenterol 2016; 22(16):4073-4078 
51 Oto A, Zhu F, Kulkarni K, Karczmar GS, Turner JR, Rubin D. Evaluation of diffusion-weighted MR imaging for detection of bowel inflammation in patients with Crohn's disease. Acad Radiol 2009;16(05):597-603

52 Punwani S, Rodriguez-Justo M, Bainbridge A, et al. Mural inflammation in Crohn disease: location-matched histologic validation of MR imaging features. Radiology 2009;252(03):712-720

53 Kiryu S, Dodanuki K, Takao H, et al. Free-breathing diffusionweighted imaging for the assessment of inflammatory activity in Crohn's disease. J Magn Reson Imaging 2009;29(04):880-886

54 Maccioni F, Viscido A, Broglia L, et al. Evaluation of Crohn disease activity with magnetic resonance imaging. Abdom Imaging 2000;25(03):219-228

55 Wagtmans MJ, van Hogezand RA, Griffioen G, Verspaget HW, Lamers CB. Crohn's disease of the upper gastrointestinal tract. Neth J Med 1997;50(02):S2-S7

56 Farman J, Faegenburg D, Dallemand S, Chen CK. Crohn's disease of the stomach: the "ram's horn" sign. Am J Roentgenol Radium Ther Nucl Med 1975;123(02):242-251

57 Annunziata ML, Caviglia R, Papparella LG, Cicala M. Upper gastrointestinal involvement of Crohn's disease: a prospective study on the role of upper endoscopy in the diagnostic work-up. Dig Dis Sci 2012;57(06):1618-1623

58 Matsumura M, Matsui T, Hatakeyama S, et al. Prevalence of Helicobacter pylori infection and correlation between severity of upper gastrointestinal lesions and $H$. pylori infection in Japanese patients with Crohn's disease. J Gastroenterol 2001; 36(11):740-747

59 Antonini F, Pezzilli R, Angelelli L, Macarri G. Pancreatic disorders in inflammatory bowel disease. World J Gastrointest Pathophysiol 2016;7(03):276-282

60 Weber P, Seibold F, Jenss H. Acute pancreatitis in Crohn's disease. J Clin Gastroenterol 1993;17(04):286-291

61 Song DJ, Whang IS, Choi HW, Jeong CY, Jung SH. Crohn's disease confined to the duodenum: a case report. World J Clin Cases 2016;4(06):146-150

62 Spiess SE, Braun M, Vogelzang RL, Craig RM. Crohn's disease of the duodenum complicated by pancreatitis and common bile duct obstruction. Am J Gastroenterol 1992;87(08):1033-1036

63 Fujiya M, Sakatani A, Dokoshi T, et al. A bamboo joint-like appearance is a characteristic finding in the upper gastrointestinal tract of Crohn's disease patients: a case-control study. Medicine (Baltimore) 2015;94(37):e1500

64 Lin J, McKenna BJ, Appelman HD. Morphologic findings in upper gastrointestinal biopsies of patients with ulcerative colitis: a controlled study. Am J Surg Pathol 2010;34(11):1672-1677

65 Ikeuchi H, Hori K, Nishigami T, et al. Diffuse gastroduodenitis and pouchitis associated with ulcerative colitis. World J Gastroenterol 2006;12(36):5913-5915

66 Ikeuchi H, Hori K, Takashi Nishigami, et al. Diffuse gastroduodenitis and pouchitis associated with ulcerative colitis. World J Gastroenterol 2006;12(36):5913-5915

67 Hisabe T, Matsui T, Miyaoka M, et al. Diagnosis and clinical course of ulcerative gastroduodenal lesion associated with ulcerative colitis: possible relationship with pouchitis. Dig Endosc 2010;22(04):268-274

68 Rogler G. Top-down or step-up treatment in Crohn's disease? Dig Dis 2013;31(01):83-90

69 Mottet C, Juillerat P, Gonvers J-J, et al. Treatment of gastroduodenal Crohn's disease. Digestion 2005;71(01):37-40

70 Tremaine WJ. Gastroduodenal Crohn's disease: medical management. Inflamm Bowel Dis 2003;9(02):127-128, discussion 131

71 Korelitz BI, Adler DJ, Mendelsohn RA, Sacknoff AL. Long-term experience with 6-mercaptopurine in the treatment of Crohn's disease. Am J Gastroenterol 1993;88(08):1198-1205

72 Griffiths AM, Alemayehu E, Sherman P. Clinical features of gastroduodenal Crohn's disease in adolescents. J Pediatr Gastroenterol Nutr 1989;8(02):166-171
73 Fielding JF, Toye DK, Beton DC, Cooke WT. Crohn's disease of the stomach and duodenum. Gut 1970;11(12):1001-1006

74 Miehsler W, Püspök A, Oberhuber T, Vogelsang H. Impact of different therapeutic regimens on the outcome of patients with Crohn's disease of the upper gastrointestinal tract. Inflamm Bowel Dis 2001;7(02):99-105

75 Grübel P, Choi Y, Schneider D, Knox TA, Cave DR. Severe isolated Crohn's-like disease of the gastroduodenal tract. Dig Dis Sci 2003;48(07):1360-1365

76 Firth MG, Prather CM. Unusual gastric Crohn's disease treated with infliximab: a case report. Am J Gastroenterol 2002;97(09): 190

77 Kawachiya T, Hara J, Hirata N, Mashimo M, Arakawa T. Successful treatment of duodenal Crohn disease with infliximab: report of 3 cases [in Japanese]. Nippon Shokakibyo Gakkai Zasshi 2010;107 (12):1933-1940

78 Murthy UK. Repeated hydrostatic balloon dilation in obstructive gastroduodenal Crohn's disease. Gastrointest Endosc 1991;37 (04):484-485

79 Matsui T, Hatakeyama S, Ikeda K, Yao T, Takenaka K, Sakurai T. Long-term outcome of endoscopic balloon dilation in obstructive gastroduodenal Crohn's disease. Endoscopy 1997;29(07): 640-645

80 Matsuhashi N, Nakajima A, Suzuki A, Akanuma M, Yazaki Y, Takazoe M. Nonsurgical strictureplasty for intestinal strictures in Crohn's disease: preliminary report of two cases. Gastrointest Endosc 1997;45(02):176-178

81 Rana SS, Bhasin DK, Chandail VS, et al. Endoscopic balloon dilatation without fluoroscopy for treating gastric outlet obstruction because of benign etiologies. Surg Endosc 2011;25 (05):1579-1584

82 Sanderson IR, Udeen S, Davies PS, Savage MO, Walker-Smith JA. Remission induced by an elemental diet in small bowel Crohn's disease. Arch Dis Child 1987;62(02):123-127

83 Buchman AL. Side effects of corticosteroid therapy. J Clin Gastroenterol 2001;33(04):289-294

84 Wall CL, Day AS, Gearry RB. Use of exclusive enteral nutrition in adults with Crohn's disease: a review. World J Gastroenterol 2013;19(43):7652-7660

85 Zachos M, Tondeur M, Griffiths AM. Enteral nutritional therapy for induction of remission in Crohn's disease. Cochrane Database Syst Rev 2007;(01):CD000542

86 Worsey MJ, Hull T, Ryland L, Fazio V. Strictureplasty is an effective option in the operative management of duodenal Crohn's disease. Dis Colon Rectum 1999;42(05):596-600

87 Salky B. Severe gastroduodenal Crohn's disease: surgical treatment. Inflamm Bowel Dis 2003;9(02):129-130, discussion 131

88 Tonelli F, Alemanno G, Bellucci F, Focardi A, Sturiale A, Giudici F. Symptomatic duodenal Crohn's disease: is strictureplasty the right choice? J Crohn's Colitis 2013;7(10):791-796

89 Campbell L, Ambe R, Weaver J, Marcus SM, Cagir B. Comparison of conventional and nonconventional strictureplasties in Crohn's disease: a systematic review and meta-analysis. Dis Colon Rectum 2012;55(06):714-726

90 Sampietro GM, Cristaldi M, Maconi G, et al. A prospective, longitudinal study of nonconventional strictureplasty in Crohn's disease. J Am Coll Surg 2004;199(01):8-20, discussion 20-22

91 Navaneethan U, Liu X, Bennett AE, Walsh RM, Venkatesh PGK, Shen B. IgG4-associated ampullitis and cholangiopathy in Crohn's disease. J Crohn's Colitis 2011;5(05):451-456

92 Rivas JM, Erim T, Berho ME, Petras RE, Castro FJ. Crohn's disease of the common bile duct and ampulla causing obstructive jaundice and acute pancreatitis. Am J Gastroenterol 2009;104 (04):1053-1055

93 Yung K, Oviedo J, Farraye FA, Becker JM, Andrews CWJ Jr, Lichtenstein D. Ampullary stenosis with biliary obstruction in duodenal Crohn's disease: a case report and review of the literature. Dig Dis Sci 2005;50(06):1118-1121 
94 Racz JM, Davies W. Severe stricturing Crohn's disease of the duodenum: a case report and review of surgical options. Int J Surg Case Rep 2012;3(07):242-245

95 Goswitz JT, Miller HP, Jacobi MA. Whipple resection for granulomatous enteritis of duodenum. Wis Med J 1971;70(09):197-199

96 Xingjun G, Feng Z, Min W, Renyi Q. Laparoscopic pancreaticoduodenectomy for the management of localized Crohn's disease of the duodenum. Indian J Surg 2016;78(04):331-333

97 Franklin RH, Taylor S. Nonspecific granulomatous (regional) esophagitis. J Thorac Surg 1950;19(02):292-297

98 De Felice KM, Katzka DA, Raffals LE. Crohn's disease of the esophagus: clinical features and treatment outcomes in the Biologic Era. Inflamm Bowel Dis 2015;21(09):2106-2113

99 Mashako MN, Cezard JP, Navarro J, et al. Crohn's disease lesions in the upper gastrointestinal tract: correlation between clinical, radiological, endoscopic, and histological features in adolescents and children. J Pediatr Gastroenterol Nutr 1989;8(04):442-446

100 Ramaswamy K, Jacobson K, Jevon G, Israel D. Esophageal Crohn disease in children: a clinical spectrum. J Pediatr Gastroenterol Nutr 2003;36(04):454-458

101 Ruuska T, Vaajalahti P, Arajärvi P, Mäki M. Prospective evaluation of upper gastrointestinal mucosal lesions in children with ulcerative colitis and Crohn's disease. J Pediatr Gastroenterol Nutr 1994;19(02):181-186

102 Decker GA, Loftus EV Jr, Pasha TM, Tremaine WJ, Sandborn WJ. Crohn's disease of the esophagus: clinical features and outcomes. Inflamm Bowel Dis 2001;7(02):113-119

103 Rudolph I, Goldstein F, DiMarino AJ Jr. Crohn's disease of the esophagus: Three cases and a literature review. Can J Gastroenterol 2001;15(02):117-122
104 D'Haens G, Rutgeerts P, Geboes K, Vantrappen G. The natural history of esophageal Crohn's disease: three patterns of evolution. Gastrointest Endosc 1994;40(03):296-300

105 Zezos P, Kouklakis G, Oikonomou A, Pitiakoudis M, Simopoulos C. Esophageal Crohn's disease treated "topically" with swallowed aerosolized budesonide. Case Rep Med 2010;2010(04):1-4

106 Bonavina L, Bettineschi F, Cecchetto A, Pomerri F. Crohn's disease of the esophagus. Dysphagia 1989;4(03):176-179

107 Hanai H, Honda S, Sugimoto K, et al. Endoscopic therapy for multiple mucosal bridges in the esophagus of a patient with Crohn's disease. Gastrointest Endosc 1999;50(05):715-717

108 Mathis G, Sutterlütti G, Dirschmid K, Feuerstein M, Zimmermann G. Crohn's disease of the esophagus: dilation of stricture and fibrin sealing of fistulas. Endoscopy 1994;26(05):508-508

109 Thomas TS, Berto E, Scribano ML, Middleton SJ, Hunter JO. Treatment of esophageal Crohn's disease by enteral feeding via percutaneous endoscopic gastrostomy. JPEN J Parenter Enteral Nutr 2000;24(03):176-179

110 Wespi SP, Frei R, Sulz MC. A very rare cause of a relapsing paraoesophageal abscess. Case Rep Gastroenterol 2016;10(01): 132-138

111 Wang W, Ni Y, Ke C, Cheng Q, Lu Q Li X. Isolated Crohn's disease of the esophagus with esophago-mediastinal fistula formation. World J Surg Oncol 2012;10(01):208-1

112 Gyde SN, Prior P, Macartney JC, Thompson H, Waterhouse JA, Allan RN. Malignancy in Crohn's disease. Gut 1980;21(12): 1024-1029

113 Rholl JC, Yavorski RT, Cheney CP, Wong RK. Esophagogastric fistula: a complication of Crohn's disease-case report and review of the literature. Am J Gastroenterol 1998;93(08):1381-1383 